made by M. F. Sy at the Algiers Observatory. Positions are given for the period April io to July Io, and the various phenomena of the head and the tail are briefly described. Observations of Venus and the comet, as suggested by Prof. Birkeland, were made, under adverse conditions, on May 2, but no special phenomena were remarked. Similar duplications of the nucleus to those recorded at Johannesburg were observed on May 3, 8, and later dates, but only a single nucleus was seen on May 5 . A notable recrudescence of brightness apparently took place on July 9, as compared with July 5 when a nebulosity, I in diameter, and no nucleus were seen. References to these alternating duplications of the nucleus are made in the December (1910) number of the Bulletin de la Societe astronomique de France, where MM. Millochau, Borrelly and others describe their observations. M. Jamain finds that the successive appearances are best explained by the supposition that the nucleus of the comet had a rotatory motion, with a period of about $2 \mathrm{r} \cdot 5$ hours.

In No. 4461 of the Astronomische Nachrichten Dr. J. Mascart reproduces three excellent photographs, and three drawings of the head, taken at his special observing station at Teneriffe during May and April respectively; the complicated structure of the head on April 16 and 18 is especially remarkable. But Dr. Mascart deals chiefly with the

\section{ON THE ORIGIN OF SLAVERY AND} PARASITISM IN ANTS.

TWO interesting papers on the origin of slavery and parasitism in ants, by Henri Pieron, Maitre de Conférences a l'Ecole pratique des Hautes-Etudes, have appeared recently in the Revue générale des Sciences (September 15 and 30,1910 ), and the main points are summarised below. The papers are conveniently divided into sections, and are rendered more valuable by full references being given for all the statements referred to.

\section{Females : Foundation of Colonies.}

(1) Foundation of a New Nest by a Fertilised Female.After the marriage-flight of ants, the males and females fall to the ground, when the males die, and those of the females which escape the numerous dangers to which they are exposed taken refuge in crevices in the ground, where they lay their eggs. For a month or more the female appears to subsist largely by the absorption of the alary muscles, now no longer required; but in some cases, as in Atta sexdens, the female carries with her a supply of the mycelium of an edible fungus, on which she and her progeny afterwards subsist. The earliest hatched workers in nests founded by a single female share her privations. being much smaller than those hatched later. In some
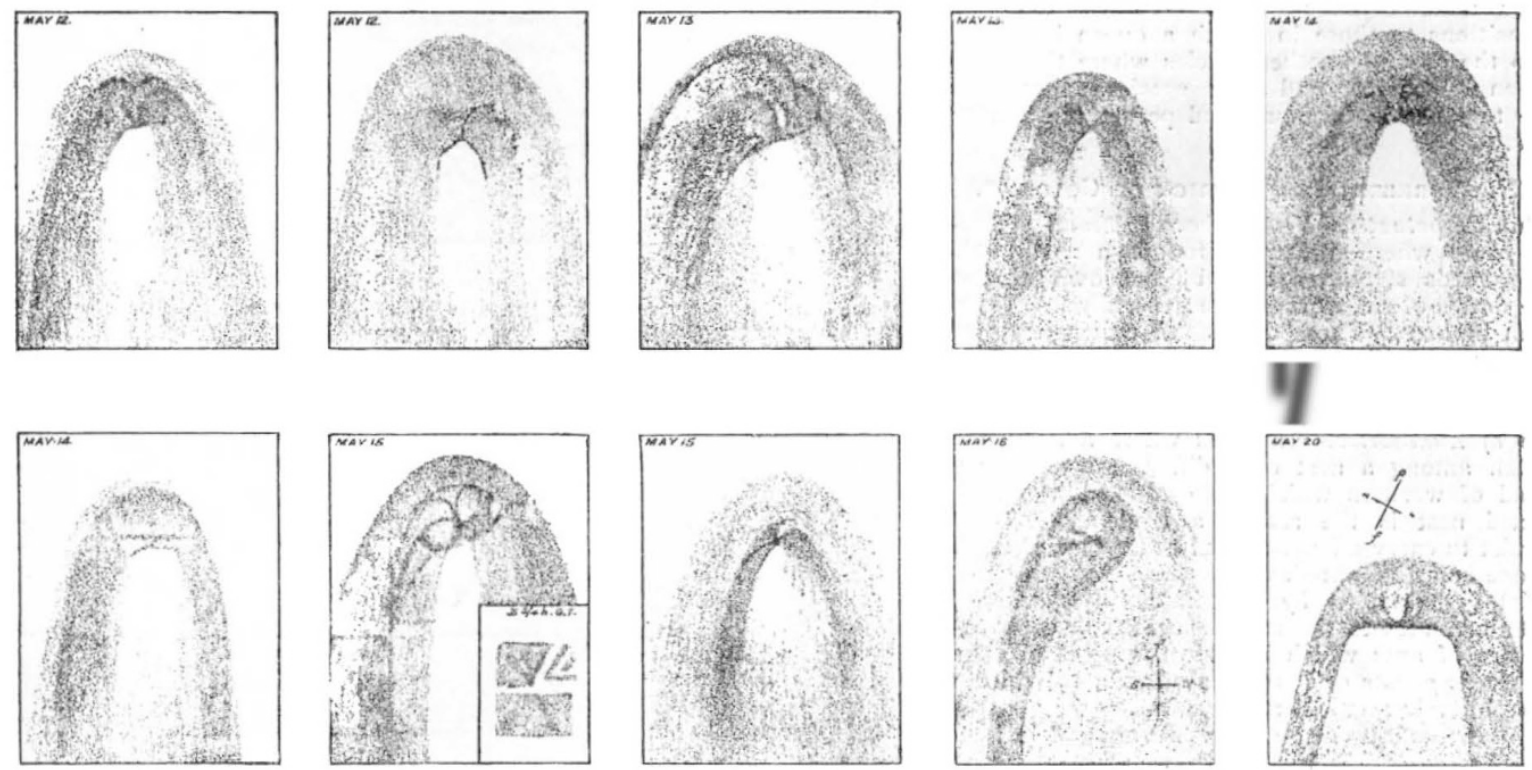

Fic. 2.-Changes in the Head of Halley's Comet, as olserved at the Transvaal Observatory.

conditions of observation on a mountain site, and strongly emphasises the advantages which accrue from the establishment of an astronomical observatory in a clear atmosphere and at a high altitude, yet more or less readily accessible. Finally, he suggests the necessity for establishing an important and permanent international observatory on Mount Guajara, where he was stationed. Dr. Mascart gives more details, and discusses such matters as the zodiacal light, \&c., in an article which appears in the December (I9Io) issue of the Rivista di Astronomia, Turin (vol. iv., No. 12, p. $5^{8} 5$ ).

A note in the December (19ro) number of the Observatory (No. 429) suggests that, as the comet has now sufficiently emerged from the sun's rays, a few more observations may be secured, even in European latitudes, before it finally disappears until August, 1985. An ephemeris for Greenwich midnight, and extending to the end of March, is given; as the declination is about $18^{\circ}$ south, those observatories situated in the southern hemisphere will enjoy better conditions. At present the comet is apparently situated in the constellation Corvus, and is travelling slowly in a south-westerly direction; its position for December 3I, I9Io, is R.A. $=1 \mathrm{Ih} .53 .4 \mathrm{~m}$. , dec. $=$ I $8^{\circ}$ I2.7 south, but after January II it will again commence to travel northwards.

$$
\text { NO. } 2 \text { I } 5 \text { O, VOL. 85] }
$$

cases a portion of the eggs are sacrificed for the nourishment of the female and the newly hatched larvæ, and are also used by $A$. sexdens as a hot-bed for the fungus. Some of the species of ants in which nests are founded by a single female are among the oldest in existence, going back, almost unchanged, to Tertiary times.

(2) Foundation of a New Colony in a Pre-existent Nest. - Female ants will sometimes take up their abode, and rear a fresh colony in the deserted nests of other species, or even, on more or less friendly terms, establish a colony of their own in inhabited nests of other species. On the other hand, ants of the genus Solenopsis, \&c., usually form nests in small galleries round and communicating with the nests of larger species, which they plunder at will, without the larger ants being able to pursue them into their narrow fastnesses.

(3) Foundation of a New Nest with the Aid of Workers of the same Species. - The females of some ants are unable to form a new colony without the aid of workers, and if they fall to the ground near their own nest, or one of the same species, they may return to the nest, or may be joined by a colony of workers, and thus assisted to establish a new one.

(4) Foundation of a New Colony with the Aid of Workers of another Species.-..Although ants usually 
destroy those of other species which enter their nests, they will sometimes receive females, especially if fertilised, into their cornmunities, whether females of their own species are living in the nest or not, and hence mixed nests of two or more species may originate. Many instances are quoted, both among European and American ants, and the author sums up the various alternatives as follows :(i) isolated workers may dig a nest for the queen and make their dwelling with her; (ii) she may be received into a nest which has lost its own queen; (iii) she may be received into a nest possessing a queen, whom she kills and supersedes; (iv) she may be received into a nest where a queen lives, whom she does not injure, but who disappears, either making her escape or being killed by the workers; (v) she may be received into a nest where the former queen remains, and continues to perpetuate her brood.

Illustrations of these alternatives are then given, with comments, and the author concludes that the formation of new colonies depends rather on the behaviour of the workers than on that of the queen.

(5) Foundation of a New Colony by Conquests of Nymphs.-This section relates to cases in which a warlike queen enters the nest of another species and drives away the adult ants, establishing herself as the queen of their undeveloped progeny. These cases form transitions to those in which a queen is received into the nest of another species where the former queen still lives, and both species subsequently live together in harmony and perpetuate a mixed nest.

\section{Workers : Perpetuation of Colonies.}

(I) Perpetuation by Workers without Allies.In cases where the queen founds a nest, and is afterwards supported only by her own progeny, the duties of the workers are generally less defined than in bees. These duties fall under four categories :-nutrition, rearing, construction and protection, and warfare.

(2) Perpetuation of a Nest with the Temporary Aid of Auxiliaries.-In cases where a female has fallen among a nest of a different species, or a band of workers which have adopted her, and a mixed nest is the result, a tendency seems to persist to carry off nymphs of other species, which is one cause of ant-slavery.

(3) Perpetuation by Nutrition (Myrmecophily). -This relates to the actual parasitism of various species of ants which inhabit the nests of others either as guests or (as in Solenopsis, to which we have already alluded) as parasites.

(4) Perpetuation by the Permanent Aid of Auxiliaries. - This relates to ant-slavery proper, where the mistresses are more or less completely dependent on their slaves for their very existence.

(5) Perpetuation in the Complete Absence of the Workers of a Species.-The strangest cases of all are perhaps those of certain species of ants which are only male and female, and which live parasitically in the nests of others. Sometimes when such a workerless queen introduces herself into a strange nest the workers kill their own queen instead of the intruder, in which case the colony is inevitably devoted to destruction by the impossibility of any further production of workers.

In his second paper M. Pieron reviews and comments on the views of Darwin, Wasmann, Wheeler, Emery, and Santschi on the various problems connected with ant-life. $\mathrm{He}$ regards Formica fusca as an ancestral form of the genus Formica, it being undistinguishable from $F$. flori found in Baltic amber, and having thrown off a series of closely related forms in most parts of the world. This ant shows the primitive stage in which the new nest is formed by the female only. Thence we pass on to $F$. rufa, of which the female can only found her nest with the aid of workers of her own or another species, and from thence to the stages of slavery and parasitism. Then $M$. Pieron discusses the general problem of the NO. 2 I 50 , VOL. 85$]$ origin of slavery and parasitism among ants, the theory of progressive stages leading to these curious habits, the explanation of the different conduct of the females, the problem of the rise of slavery and parasitism among neuters, and the origin of aid and tolerance towards intruders of other species. His final conclusion seems to be that in proportion as evolution leads further and further from a primitive state, insects, like men, become more and more dependent on each other. Among ants, those with the simplest and most primitive habits are the most abundant, while as they become slave-holders, and later on parasites, their colonies and individuals become rarer and rarer. It is evident that when ultra-civilisation degenerates into slavery and parasitism it is neither good for man nor ant.

\section{TEMPERATURE CHANGES AND SOLAR} ACTIVITY.

PROF. F. H. BIGELOW (American Journal of Science,

vol. xxx., August, I9Io, p. I15) has been discussino the variations of the mean annual temperature of the United States of America and their relation to the changes of solar activity as shown by the frequency of sun-spots and prominences.

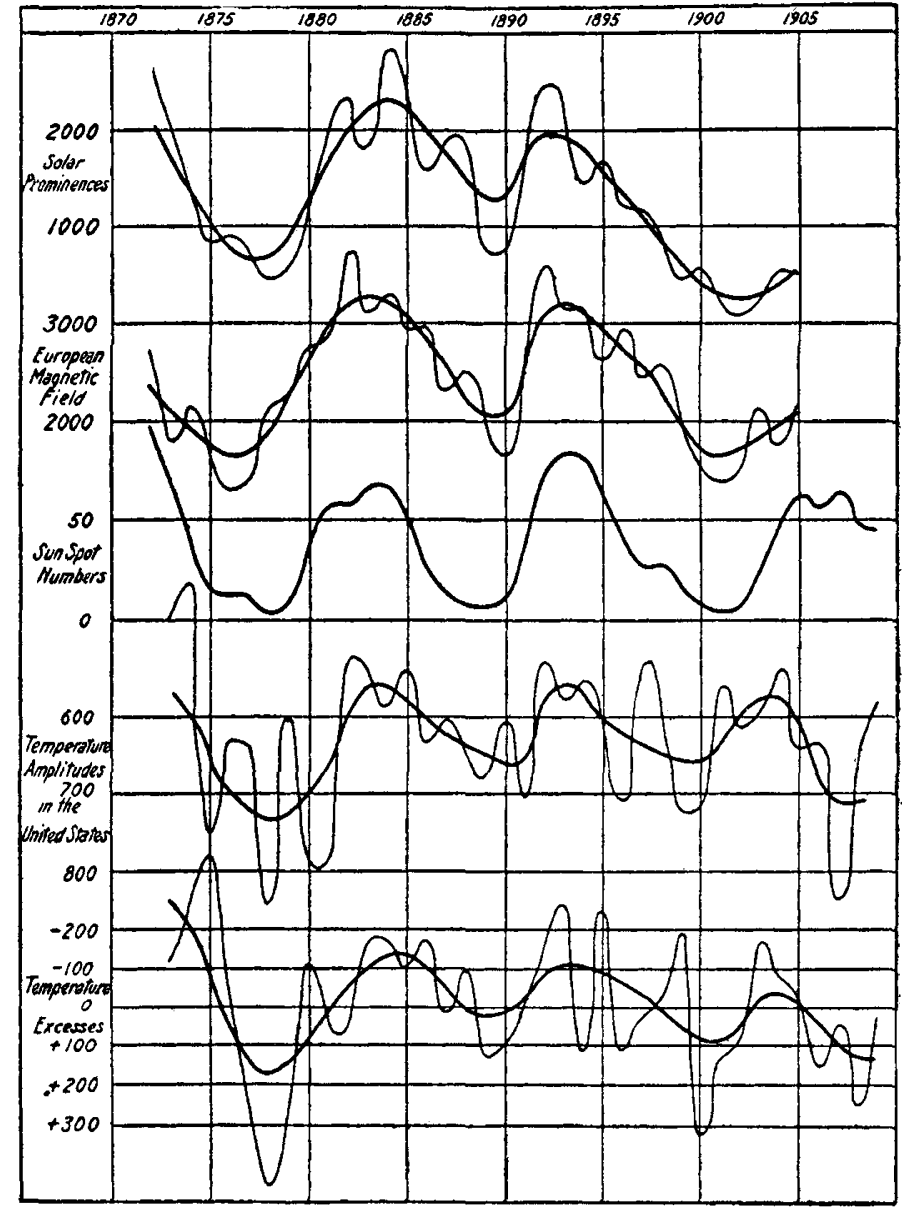

Prominences, magnetic field, sun-spots and the temperature amplitudes and excesses of

To arrive at a correct estimate of the mean temperature of the States and the departure from the mean for thirty-three years, monthly maps showing the departures of about Ioo stations were prepared, and lines of equal departures drawn. The product of the area under one sign and the departure gives a "temperature volume." The difference between the negative and positive "temperature 